\title{
Biochemical Performance and Quantitative Assessment of F1 Hybrid of Two Ecoraces of Tropical Tasar Silkworm Antheraea Mylitta Drury (Lepidoptera: Saturniidae)
}

\author{
Gangadharaiah Lokesh ${ }^{1 *}$, Sushma Rani Tirkey ${ }^{2}$, Ashok Kumar Srivastava ${ }^{1}$, Prasant Kumar $\operatorname{Kar}^{1}$, and \\ Manoj Kumar Sinha ${ }^{1}$ \\ ${ }^{1}$ Silkworm Breeding \& Genetics, Central Tasar Research \& Training Institute, Central Silk Board, Ranchi, 835303, India \\ ${ }^{2}$ Department of Biotechnology, Marwari College, Ranchi, India
}

\section{Abstract}

Antheraea mylitta Drury is basically a crossbreeding species, as such it seems to be potentially a good material for the exploitation of heterosis. In the present study F1 hybrid of wild ecorace Laria (L) and semi-domestic Daba (D) was raised and evaluated for various quantitative traits and biochemical parameters during larval stage. Improved fecundity $(+18$ $\pm 1.8 \%)$ and higher egg hatching rate $(+10.96 \pm 1.3 \%)$ was recorded in the F1hybrid $(L \times D)$. Biochemical parameters studied in the hemolymph, midgut and fatbody of the larva showed significantly higher $(P<0.05)$ total proteins and carbohydrate concentration besides digestive enzyme activity. Correspondingly SDS-PAGE revealed more number of protein bands in the hemolymph sample of $\mathrm{F} 1 \mathrm{~s}$, ranging between $29 \mathrm{kDa}$ to $66 \mathrm{kDa}$ compared to parental lines. The present study demonstrates the positive heterosis effect in the F1 hybrid of Laria $\times$ Daba. Biochemical analysis indicates that, there is possibilities of exploitation of hybrids with specific parents targeted for desirable commercial traits (silk yield and fecundity). Moreover, most of these biochemical parameters can be used as markers to analyze the genetic improvement in the tasar silkworms.

Received : 1 Apr 2013

Accepted : 27 May 2013

Keywords:

F1 hybrid,

Antheraea mylitta,

Proteins,

Daba,

Laria,

Ecoraces

\section{Introduction}

Tropical tasar culture involves rearing of tropical tasar silkworm Antheraea mylitta Drury in the forest or economic plantation of tasar food plants to produce tasar cocoons which further processed to extract world famous vanya silk. Presently, the annual contribution of tasar raw silk is about 1590 MT (2011-12) which has substantial demand in the international market. Tasar silkworm is a polyphagous insect and differs in its adaptation on different food plants (Suryanarayana et al., 2005). The tropical tasar silkworm populations occupying in different ecological and geographical regions show extensive phenotypic variability (Jolly et al., 1968; Sengupta et al., 1993; Singh and Srivastava, 1997; Srivastava et al., 2003; Suryanarana and Srivastava, 2005) for which they are known as 'ecoraces'. About 44 ecoraces

\section{*Corresponding Author :}

G. Lokesh

Silkworm Breeding \& Genetics, Central Tasar Research \& Training Institute, Ranchi 835303, India Tel: +91-8986653404

E-mail: lokesh10csb@gmail.com 
have been identified throughout India. Tasar silkworm is basically a cross breeding species, as such it seems to be potentially a good material for the exploitation of heterosis (Sengupta et al., 1987). Since, variability being the genetic basis of any crops this is the basic requirement for genetic improvement. Therefore, in order to create new reservoirs of genetic variability, the use of crossing method the most genetically diverse parents has become essential as it helps in recombination of genes from diverse sources. The existing genetic variation among wild and domesticated sericigenous insects needs exploitation through hybridization for better quantitative and qualitative traits (Reddy et al., 2008). To develop productive hybrids and high yielding segregates in $A$. mylitta, the pre-requisites are selection of genetically divergent parental ecoraces, identification of commercial traits with heterosis potential (Reddy et al., 2010; Sengupta et al., 1987; Siddiqui, 1997). The present study was to explore the potentialities of F1 hybrid produced from a wild ecorace Laria crossed with semi-domestic Daba ecorace of $A$. mylitta.

\section{Material \& Methods}

Experiments of present work were undertaken at Silkworm Breeding and Genetics laboratories and rearing of silkworms at the farm of Central Tasar Research \& Training Institute, Ranchi during the second crop rearing season (September-November, 2012).

\section{Grainage and raising of $\mathrm{F} 1$ hybrid}

Grainage was conducted during September 2012, Daba cocoons harvested during the first crop (July-August 2012) were collected from the Germplasm bank, Silkworm breeding section, Central Tasar Research \& Training Institute. Laria cocoons were collected from forest area of Peterbar, Jharkhand. The good cocoons were sorted based on the sex. A total of 100 male and identical numbers of female cocoons each of two ecoraces were selected and stored at normal grainage conditions until the emergence of moth. When emergence started, crossings were made as Laria $\mathrm{x}$ Daba, besides the parental stocks. Mated female moths of all the batches were kept for oviposition for 3 days at normal grainage conditions.

\section{Fecundity and egg hatching}

The fecundity was calculated as total number of eggs laid by a single mother moth in three days of egg laying (Sinha, 1998). Hatching rate was recorded (Saheb et al., 2009) and expressed in percentage.

\section{Preparation of samples for biochemical studies}

Hemolymph, fat body and midgut of Daba, F1 hybrid and Laria of both the sexes were collected separately during $5^{\text {th }}$ day of $\mathrm{V}$ instar for the biochemical studies which is known to be the most active stage of tasar silkworm in terms of metabolism. Hemolymph and fat body samples were collected by dissecting out the larva and further processed (Lokesh et al., 2012b). Midgut was collected by separating anterior and posterior part of the gut and transferred to a pre-cooled plastic vials and stored at $-20^{\circ} \mathrm{C}$ until further use. Subsequently the tissues were homogenized with appropriate buffer, diluted and the supernatants were used for biochemical analysis.

\section{Biochemical analysis}

The total protein concentration was assayed as described by Lowry et al., (1951), total carbohydrates was determined according to Sinha et al., (1998). The digestive enzymes viz., amylase activity and protease activity were analyzed in the larval midgut and hemolymph. Soluble starch was used as a substrate to analyze the amylase activity as mentioned by Ishaaya and Swirsky (1976). Protease was assayed according to Eguchi and Iwamoto (1982). Acid phosphatase activity was recorded in the hemolymph and midgut as mentioned earlier by Gaikwad et al (2010). Alkaline phosphatase was analyzed in the larval midgut by the method described by Wilson and Walker (2000). The qualitative analysis of total soluble protein was done in haemolymph by using the SDS-PAGE as described by Zingales (1984).

\section{Statistical analysis}

The date generated in the present study is the average values of three replicates ( $\mathrm{n}=5$ for biochemical analysis and $\mathrm{n}=100$ for quantitative trait analysis). One-way ANOVA was carried out using SPSS 10.0 statistical package to test the significance 
Table 1. Fecundity and egg hatching of Daba, Laria and F1 hybrid (Mean \pm SE)

\begin{tabular}{|ccc|}
\hline & $\begin{array}{c}\text { Fecundity } \\
\text { (nos.) }\end{array}$ & $\begin{array}{c}\text { Egg hatching } \\
(\%)\end{array}$ \\
\hline Daba & $225 \pm 6.80$ & $83 \pm 2.64$ \\
\hline Laria & $201 \pm 5.13$ & $72 \pm 3.05$ \\
\hline$F_{1}$ hybrid & $253 \pm 9.84$ & $86 \pm 2.08$ \\
\hline
\end{tabular}

of differences, between the means of individuals and among the groups studied. Comparisons were performed with Duncan's Multiple Range Test (DMRT, $\mathrm{P}<0.05$ ) (Duncan, 1955).

\section{Results}

The performance of the F1 hybrid (Laria x Daba) tasar silkworm was analyzed and compared with its parental lines for fecundity, egg hatching and biochemical parameters are recorded.

\section{Fecundity and Egg hatching}

The performance of F1 hybrid was recorded with significant improvement in the fecundity $(P<0.05)$ over its parental lines (Table 1). The fecundity was $253 \pm 6.51$ in F1 hybrid compare to the parental lines, Daba $225 \pm 5.74$ and Laria 201 \pm 7.91 there was a genetic gain of about $18 \%$ over the mid parent value for the fecundity. Higher hatching was recorded in the F1 hybrids (86\%) compared to the parental lines, Daba $83 \%$ and Laria recorded $72 \%$ of hatching in three days.

\section{Total protein concentration}

Protein concentration was recorded highly variable between the different batches (Daba, Laria and F1 hybrid) and the tissues studied. Higher protein concentration was recorded in the hemolymph of F1 hybrid female larvae $(372.00 \pm 1.73 \mathrm{mg} / \mathrm{ml})$ followed by Daba female larval hemolymph $(368.00 \pm 1.15 \mathrm{mg} / \mathrm{ml})$ and the lowest concentration $(106.00 \pm 1.73 \mathrm{mg} / \mathrm{ml})$ was recorded in the fat body of male Laria larva. A significant increase in the protein concentration $(P<0.05)$ in the $\mathrm{F} 1$ hybrid was recorded, the values obtained is higher than either of the parents. Also, variability in the protein concentration among the tissues studied, higher proteins was observed in the hemolymph followed by midgut tissue and fat body (Table 2). Sexual dimorphism was very much apparent, where higher protein concentration was observed in females of all the batches when compared to males.

\section{Total Carbohydrates}

The level of carbohydrates was recorded the significantly higher $(P<0.05)$ in the F1 hybrid compared to the parental lines (Table 2). It was $42.13 \pm 0.88 \mathrm{mg} / \mathrm{ml}$ and $37.30 \pm 0.57$ in the hemolymph, $32.40 \pm 0.57$ and $30.10 \pm 01$ in midgut tissue and $25.10 \pm 1.15$ and $23.90 \pm 1.15 \mathrm{mg} / \mathrm{ml}$ in fat body of F1 hybrid. The lower values $(22.10 \pm 1.15$ and $23.90 \pm 1.15 \mathrm{mg} / \mathrm{ml})$ for total carbohydrates were recorded in the fat body of Laria ecorace followed by fat body of Daba $(21.96 \pm 1.45 \& 24.80 \pm 2.30 \mathrm{mg} / \mathrm{ml})$ and F1 hybrid $(23.90 \pm 1.15 \& 25.10 \pm 1.15 \mathrm{mg} / \mathrm{ml})$.

\section{Digestive enzymes}

The level of activity showed significant variations among the larval batches viz., Daba, Laria and F1 hybrid. Significantly higher $(P<0.05)$ activity was found in the midgut tissue of $\mathrm{F} 1$ hybrid larvae (male $0.820 \pm 0.011$ and female $0.79 \pm 0.017 \mu \mathrm{M} / \mathrm{ml}$ of homogenate) compared to other samples. Similar observations were made in the level of the protease activity. Activity found minimum in Laria larval hemolymph. Higher activity was found in mid gut tissue of all the batches compared to enzyme activity in hemolymph (Table 3).

\section{Acid and Alkaline phosphatase}

An increase in the phosphatase activity was found in the midgut tissue of F1 hybrid larva the level of the activity was significantly higher to the parental lines (Table 4).

\section{Electrophoresis of hemolymph protein}

Qualitative analysis of haemolymph proteins in the $\mathrm{V}$ instar larva of Daba, Laria and F1 hybrid of tasar silkworm was recorded (Fig. 1) Polymorphic variations were noticed with regard to the number of protein bands in male and female also in different batches viz., Daba, Laria and F1 hybrid. Protein bands of 98 KDa, 70 kDa, 45 
Table 2. Quantitative analysis of total protein and carbohydrate concentrations in the different tissues of Daba, Laria \& F1 hybrid (Mean $\pm \mathrm{SE})$

\begin{tabular}{|c|c|c|c|c|c|c|c|c|c|c|c|c|}
\hline & \multicolumn{6}{|c|}{ Protein concentration (mg/g tissue) } & \multicolumn{6}{|c|}{ Total Carbohydrates (mg/g tissue) } \\
\hline & \multicolumn{2}{|c|}{ Daba } & \multicolumn{2}{|c|}{ Laria } & \multicolumn{2}{|c|}{ F1 hybrid } & \multicolumn{2}{|c|}{ Daba } & \multicolumn{2}{|c|}{ Laria } & \multicolumn{2}{|c|}{$F_{1}$ hybrid } \\
\hline & M & F & M & $\mathbf{F}$ & M & $\mathbf{F}$ & M & $\mathbf{F}$ & M & $\mathbf{F}$ & M & $F$ \\
\hline hemo- & 308 & 368 & 293 & 318 & 355 & $372^{* *}$ & 33.13 & 38.67 & 30.10 & 36.30 & 37.30 & $42.13^{\star *}$ \\
\hline lymph & \pm 1.15 & \pm 1.15 & \pm 1.15 & \pm 0.57 & \pm 1.15 & \pm 1.73 & \pm 1.15 & \pm 1.27 & \pm 1.15 & \pm 1.73 & \pm 0.57 & \pm 0.88 \\
\hline fat hodv & 114 & 123 & 106 & 116 & 123 & 135 & 21.97 & 4.80 & 22.10 & 23.90 & 23.90 & $25.10^{* *}$ \\
\hline Iat Dody & \pm 0.57 & \pm 1.15 & \pm 1.73 & \pm 1.15 & \pm 1.73 & \pm 1.15 & \pm 1.45 & \pm 2.30 & \pm 1.15 & \pm 1.15 & \pm 1.15 & \pm 1.15 \\
\hline midgut & 190 & 250 & 178 & 225 & 222 & $283^{* *}$ & 28.10 & 29.80 & 27.30 & 28.50 & 30.10 & $32.40^{* *}$ \\
\hline Tinagut & \pm 1.73 & \pm 2.88 & \pm 1.73 & \pm 2.88 & \pm 1.00 & \pm 1.15 & \pm 1.00 & \pm 1.15 & \pm 1.15 & \pm 0.57 & \pm 1.00 & \pm 0.57 \\
\hline \multicolumn{7}{|c|}{ F value: $3786.557 \mathrm{CD}$ at $5 \%$} & \multicolumn{6}{|c|}{ F value: $25.725 \mathrm{CD}$ at $5 \%$} \\
\hline
\end{tabular}

** Significant at $p<0.05, \mathrm{M}-$ Male, F - Female

Table 3. Activity analysis of digestive enzymes in the different tissues of Daba, Laria \& F1 hybrid (Mean $\pm \mathrm{SE}$ )

\begin{tabular}{|c|c|c|c|c|c|c|c|c|c|c|c|c|}
\hline & \multicolumn{6}{|c|}{$\begin{array}{c}\text { Amylase activity } \\
\text { ( } \mu \text { mole maltose/min/mg protein ) }\end{array}$} & \multicolumn{6}{|c|}{$\begin{array}{c}\text { Protease activity } \\
\text { ( } \mu \text { mole tyrosine/min/mg protein ) }\end{array}$} \\
\hline & \multicolumn{2}{|c|}{ Daba } & \multicolumn{2}{|c|}{ Laria } & \multicolumn{2}{|c|}{ F1 hybrid } & \multicolumn{2}{|c|}{ Daba } & \multicolumn{2}{|c|}{ Laria } & \multicolumn{2}{|c|}{ F1 hybrid } \\
\hline & M & $\mathbf{F}$ & M & $\mathbf{F}$ & M & $\mathbf{F}$ & M & $\mathbf{F}$ & M & $\mathbf{F}$ & $\mathbf{M}$ & $\mathbf{F}$ \\
\hline hemo- & 0.51 & 0.55 & 0.47 & 0.50 & 0.55 & 0.61 & 0.75 & 0.79 & 0.70 & 0.72 & 0.79 & 0.82 \\
\hline lymph & \pm 0.00 & \pm .01 & \pm 0.01 & \pm 0.11 & \pm 0.01 & \pm 0.00 & \pm 0.01 & \pm 0.01 & \pm 0.00 & \pm 0.01 & \pm 0.00 & \pm 0.01 \\
\hline & 0.69 & 0.78 & 0.62 & 0.71 & 0.82 & $0.79^{* *}$ & 0.90 & 0.92 & 0.85 & 0.88 & 0.95 & $0.99^{* *}$ \\
\hline midgut & \pm 0.11 & \pm 0.00 & \pm 0.00 & \pm 0.01 & \pm 0.01 & \pm 0.01 & \pm 0.00 & \pm 0.00 & \pm 0.01 & \pm 0.00 & \pm 0.01 & \pm 0.00 \\
\hline \multicolumn{7}{|c|}{ F value: $6.415 \mathrm{CD}$ at $5 \%$} & \multicolumn{6}{|c|}{ F value: $109.597 \mathrm{CD}$ at $5 \%$} \\
\hline
\end{tabular}

** Significant at $p<0.05, \mathrm{M}-$ Male, F - Female

Table 4. Activity analysis of Acid and Alkaline Phosphatase in the different tissues of Daba, Laria \& F1 hybrid (Mean \pm SE)

\begin{tabular}{|c|c|c|c|c|c|c|c|c|c|c|c|c|}
\hline & \multicolumn{6}{|c|}{$\begin{array}{c}\text { Acid Phosphatase } \\
\text { ( } \mu \mathrm{g} \text { p-nitro phenol/mg protein) }\end{array}$} & \multicolumn{6}{|c|}{$\begin{array}{l}\text { Alkaline Phosphatase (midgut) } \\
\text { (jg p-nitro phenol/mg protein) }\end{array}$} \\
\hline & \multicolumn{2}{|c|}{ Daba } & \multicolumn{2}{|c|}{ Laria } & \multicolumn{2}{|c|}{ F1 hybrid } & \multicolumn{2}{|c|}{ Daba } & \multicolumn{2}{|c|}{ Laria } & \multicolumn{2}{|c|}{ F1 hybrid } \\
\hline & M & $F$ & M & $F$ & M & $F$ & M & $F$ & M & $\mathbf{F}$ & M & F \\
\hline hemo- & 43.6 & 47.1 & 41.8 & 44.5 & 44.5 & 47.8 & ND & ND & ND & ND & ND & ND \\
\hline lymph & \pm 0.57 & \pm .1 .15 & \pm 1.15 & \pm 0.57 & \pm 0.01 & \pm 1.15 & & & & & & \\
\hline \multirow{2}{*}{ midgut } & 54.4 & 58.1 & 53.0 & 55.9 & 60.1 & $66.3^{* *}$ & 25.07 & 27.8 & 20.3 & 24.3 & 24.9 & $27.2^{\star \star}$ \\
\hline & \pm 0.57 & \pm 1.73 & \pm 1.15 & \pm 1.15 & \pm 0.57 & \pm 1.15 & \pm 0.57 & \pm 1.15 & \pm 1.15 & \pm 1.15 & \pm 1.15 & \pm 0.57 \\
\hline \multicolumn{13}{|c|}{ F value: $57.853 \mathrm{CD}$ at $5 \%$} \\
\hline
\end{tabular}

** Significant at $p<0.05, \mathrm{M}-$ Male, F - Female, ND - Not determined 


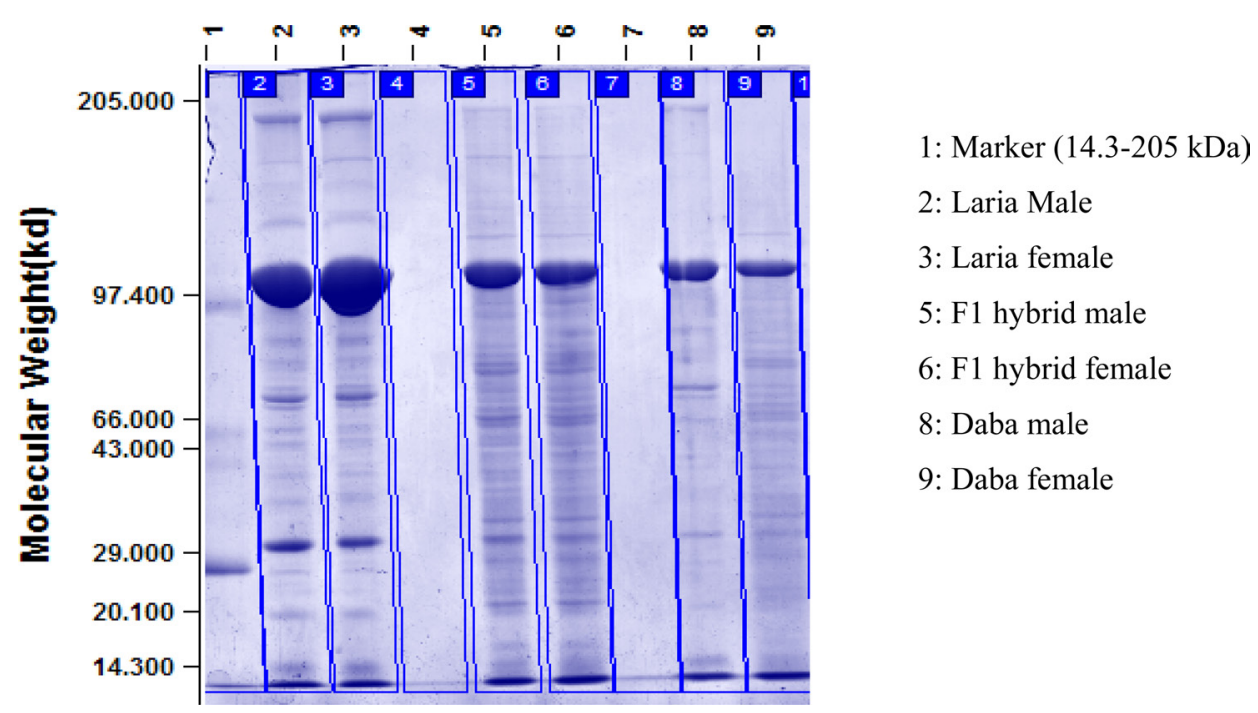

Fig. 1. Electrophoresis analysis of $5^{\text {th }}$ Instar tasar silkworm larval hemolymph of Daba, Laria and F1 hybrid.

$\mathrm{kDa}, 28 \mathrm{kDa}$ and $14 \mathrm{kDa}$ are found common in all the hemolymph samples. Additional number of protein bands was recordedd in the hemolymph sample of F1 hybrid ranging between $29 \mathrm{kDa}$ to $66 \mathrm{kDa}$ compared to the samples of Daba and Laria. Conspicuously stained bands of $67 \mathrm{kDa}$ appeared in the hemolymph samples of F1 hybrid.

\section{Discussion}

The quantitative characters in silkworm are highly variable and have a greater economic value. F1 hybrids are most commonly used for commercial cocoon production because they represent high heterosis for most of the economic characters (Singh et al, 2012). Earlier, it has been reported that F1 hybrids are less variable than parental lines, three-way and double crosses. The heterosis in silkworm, many characters have been found to have a relationship with the qualitative and quantitative aspects of silk yield (Ohio et al, 1970). The improvement observed in some of the quantitative traits of the F1 hybrid in relation to fecundity and egg hatching/fertility in present study shows a positive heterosis effect as a result of genetically divergent crosses. Fecundity is considered as one of the most desired quantitative traits of commercial importance in silkworms (Reddy et al., 2010). The genotype-environment interaction has highly significant influence on the fecundity of the silkworms, the differential performance between the groups viz., F1 hybrid, Daba and Laria with reference to fecundity attributed to the genetic endowment of the two ecoraces (Omana and Gopinathan, 1995). Similarly the egg hatching is depends on the fertilization of eggs and proper development of embryo inside the egg (Saheb et al., 2009). The higher fecundity and hatching rate might be due to the epistasis effect as a result of crossing two different tasar silkworm ecoraces (Falconer, 1985; Aruga, 1994; Reddy et al., 2010) also this can be attributed that positive gain in the silkworm traits might be due to expression of dominant gene(s) for a character (Verma et al., 2005; Reddy et al., 2008).

Higher concentration of the total protein and carbohydrates recorded in the present study for F1 hybrid is attributed to the fact that these larvae have acquired robustness due to the interecoracial crossing and fed higher quantity and quality leaves in turn efficiently converted the dietary food during its feeding stage, the corresponding level of proteins were maintained in the hemolymph, midgut and fat body. Also, many authors have similarly recorded higher proteins in the hemolymph of female earlier (Babu et al. 2009; Kumar et al., 1998; Lokesh et al., 2012a; Kumar et al., 2011; Srivastava et al., 2001). The differential concentration recorded in different batches viz., Daba Laria and F1 hybrid depicts the differential feeding rate and physiological activity among different ecoraces and adaptively for the geographical region and food plant (Venugopala Pillai et al., 1987). The digestive enzymes viz., amylase and protease in both midgut and haemolymph of tropical tasar silkworms revealed that the activity was higher in the midgut compared to hemolymph. This is mainly due to the fact that, the maximum leaves consumed by the larvae were during that period and the presence of food in the gut may act as a stimulus for the 
secretion of enzymes similar to the findings of Lokesh and Ananthanarayana (2012) observed in the silkworm Bombyx mori. Ishaaya et al. (1971) showed in the larvae of Spodoptera littoralis that the protein factors act as stimulation for digestive enzymes probably through a hormonal mechanism. Higher quantity of food accumulated in the digestive tract, leads for more secretion of digestive enzymes in the midgut (Waldbauer, 1968). Acid and Alkaline phosphatases are hydrolases, is a group of enzymes that catalyzes the hydrolysis of a chemical bond during a metabolic process and is mainly involved in lysosomal activities. The significant increase in the levels of key hydrolases such as acid and alkaline phosphatases in silk gland and fat body may be due to the rupturing of various cellular and lysosomal membranes that contain the hydrolytic enzymes, resulting in an increase in their activities (Singh et al., 2010) .The higher acid and alkaline phosphatase activity recorded in the mid gut of F1 hybrid is in corresponding with the level of other digestive enzyme activity. Where, phosphatases hydrolyse variety of phosphate monoesters of consumed leaves in the larval gut and transphosphorylated into silkworm biomolecules. The level of phosphatase activity in the mid gut is correlated with that of silk protein synthesis level and absorption capacity of digested food in the silkworm larvae (Gaikwad et al., 2010).

Study of protein banding patterns by SDS-PAGE in the hemolymph samples drawn from different larval batches revealed that the number of protein bands and specificity of bands vary between the larval batches and also between male and female. The presence and absence of few protein bands at different molecular weight indicates the synthesis of a particular protein to meet the physiological need. Protein bands of $98 \mathrm{kDa}, 70 \mathrm{kDa}, 45 \mathrm{kDa}$, $28 \mathrm{kDa}$ and $14 \mathrm{kDa}$ are found common in all the hemolymph samples of all the larva batches. This could be of species specific proteins, presumed to found in all the ecoraces of the $A$. mylitta. Kumar et al., (2011) showed the protein bands of 36 and $64 \mathrm{kDa}$ are constitutively appeared in all the tissues studies in A. mylitta. More number of protein bands was observed in the hemolymph sample of F1 hybrid between $66 \mathrm{kDa}$ to $29 \mathrm{kDa}$ compared to the samples of Daba and Laria. This is attributed to the higher protein concentration recorded in the hemolymph of F1 hybrid. Conspicuous bands of $67 \mathrm{kDa}$ are appeared in the hemolymph samples of F1 hybrid can be interpreted that higher synthesis of this protein. The higher number of protein bands in the F1 hybrid indicated the improvement of protein synthesis and concentration over its parental lines i.e., Daba and Laria.

Better performance of $\mathrm{F}$ hybrid of Laria $\mathrm{x}$ Daba in almost all the parameters studied in the present study indicates the possible influence of hybridization. Also a positive heterosis effect in the F1 hybrid this envisages the possible utilization of F1 hybrids from the crosses of wild and semi-domesticated ecoraces of tropical tasar silkworm for optimal silk productivity. However, biochemical analysis envisages that, there will be possibilities of breeding with specific parents obtaining desirable commercial traits (silk yield and fecundity) are an impending tool to optimize heterosis for genetic improvement in the desired direction. Moreover, these biochemical parameters can be used as markers to analyze the genetic improvement in the tasar silkworms especially in hybrids.

\section{References}

Aruga H (1994) Principles of Sericulture. Oxford and IBH Publishing Co. Pvt. Ltd., New Delhi, pp 99-111.

Babu KR, Ramakrishna S, Reddy YHK, Lakshmi G, Naidu NV, Basha SS, et al. (2009) Metabolic alterations and molecular mechanism in silkworm larvae during viral infection: A review Afr J Biotech 8, 899907.

Duncan DB (1955). Multiple range and multiple F- tests. Biometrics 11, $1-42$

Eguchi M , Iwamoto A (1982) Comparison of three alkaline proteases from digestive fluid of the silkworm, Bombyx mori. L. Comp Biochem Physiol 71 b, 663-668.

Falconer DS (1985) Introduction to Quantitative Genetics, ELBS, Longman, London.

Gaikwad YB, Gaikwad SM, Bhawane GP (2010) Effect of induced oxidative stress and herbal extracts on acid phosphatase activity in lysosomal and microsomal fractions of midgut tissue of the silkworm, Bombyx mori. J Insect Sci 10, 113

Ishaaya I, Swirski E (1976) Trehalase, invertase and amylase activities in the black scale, Saissetia oleae and their relation to host adaptability. J Insect Physiol. 22, 1025-1029.

Ishaaya I, More I, Joseph D (1971) Protease and amylase activity in larvae, of Egyptian cotton worm Spodoptera littoralis. J Insect Physiol 17, 945-953.

Jolly MS, Chaturvedi SN, Prasad S (1968) A survey of tasar crops in India. Indian J Seric 1, 50-58.

Kumar D, Pandey JP, Jain J, Mishra PK, Prasad BC (2011) Qualitative and 
Quantitative changes in protein profile of various tissue of tropical tasar silkworm, Antheraea mylitta Drury. Int. J Zool Res 7(2), 147 -155.

Kumar NK, Ismail SM, Dutta A (1998) Differential uptake of storage protein by the fat body of Rice moth, Corcyra cephalonica during the larval pupal development. Entomon 23, 83-90.

Lokesh G, AnanthaNarayana SR (2012) Changes in the activity of digestive enzymes in response to the chemical mutagen Diethyl Sulfate in the silkworm Bombyx mori. L (Lepidoptera: Bombycidae).Asian J Appl Sci 5 (6), 431-437.

Lokesh. G, Kar PK, Srivastava AK, Saloni Swaroopa, Sinha M K (2012a) Studies on the high temperature induced stress on the biochemical profile and fecundity of Daba and Laria ecoraces of tropical tasar silkworm Antheraea mylitta Drury (Lepidoptera: Saturniidae). Int J Indust Entomol 24(1), 69-74.

Lokesh G, Putkho PP, Madhusudhan KN, Kar PK, Srivastava AK, Sinha MK, et al (2012b) Study of Phenotypic Variability in Silk Gland Characters in Three Ecoraces of Tropical Silkworm Antheraea mylitta Drury. Asian J Anim Vet Adv 7(1), 80-84.

Lowry OH, Rosebrough NJ, Farr AL, Randall RJ, (1951) Protein measurement with Folin phenol reagent. J Biol Chem 193, 267-275.

Ohio H, Miyahara J, Yamashita A (1970) Tech Bull Sericult Expt Stn Japan, MAFF 93, 39-49.

Omana J, Gopinathan KP (1995) Heat shock response in mulberry silkworm races with different thermo tolerances. J Bioscience 20(4), 499513.

Reddy RM, Suryanarayana N, Vijaya Prakash NB (2008) Heterosis potential in selective parental F1 hybrids of divergent geographic ecoraces of tropical tasar silkworm, Antheraea mylitta D (Lepidoptera Saturniidae) Acad J Entomol 1, 32-35.

Reddy RM, Suresh Rai, Srivastava AK, Kar PK, Sinha MK, Prasad BC (2010) Heterosis pattern and commercial prospective of Assorted F1 hybrids of Indian tropical tasar silkworm, Antheraea mylitta Drury. J Entomol 7(3), 160-167.

Saheb Biram NM, Tribhuwan Singh and Saratchandra B (2009) Occurrence of Unfertilized eggs in the mulberry silkworm Bombyx mori L (Lepidoptera: Bombycidae). Int J Indus Entomol 18(1), 1-7.

Sengupta AK, Siddiqui AA, Dasmohapatra DP, Kumar A, Sengupta K (1987) Studies on the potentials of heterosis in tropical tasar Antheraea mylitta Drury. Sericologia 27, 519-524.

Sengupta AK, Sinha AK, Sengupta K. (1993) Genetic reserves of Antheraea mylitta Drury. Indian silk 32, 39-46.

Siddiqui AA (1997) Studies onheterosis and heterobeltosis in the tasar silkworm Antheraea mylitta D. Sericologia 37, 59-65.
Singh Anita, Ratnesh KS and Bechan Sharma (2010) Low temperature induced alterations in certain biochemical constituents of 5th instar larvae of Philosamia ricini (Lepidoptera: Satunidae) Open Access Insect Physiology 2, 11-16.

Singh BMK, Srivastava AK(1997) Ecoraces of Antheraea mylitta Drury and exploitation strategy through hybridization: Current Technology Seminar on Non-Mulberry Sericulture, CTR\&TI, Ranchi, India Base paper 6. pp 1-39,

Singh Tribhuwan, Pramod KS and Khurshid AS (2012) The Heterosis Phenomenon in Mulberry Silkworm, Bombyx mori L (Lepidoptera: Bombycidae). Annals of Bio Res 3(9), 4330-4336.

Sinha BRRP (1998) Survey of genetic resources and study of the genetic divergence in Antheraea mylitta Drury. Ph.D. Thesis, Ranchi University, Ranchi, India.

Sinha USP, Sinha AK, Brahmachari BN, Sinha SS (1998) Seasonal variations in the carbohydrate content during different larval stages of Tasar silkworm, Antheraea mylitta Drury. Sericologia 38, 385-388.

Srivastava AK, Kar PK, Naqvi AH, Sinha AK, Singh BMK, Sinha BRRP, et al. (2001) Biochemical variation in ecoraces of Antheraea mylitta : A review. Perspectives in Cytology \& Genetics 10: 359-346

Srivastava AK, Sinha AK, Sinha BRRP (2003) Descriptor of tropical tasar silkworm, Antheraea mylitta Drury (Lepidoptera Saturniidae). CTR\&TI, Ranchi 1-14.

Suryanarayana N, Kumar R and Gargi (2005) Monograph on Indian tropical tasar silkworm food plants (Terminalia Spp.) Central Tasar Research and Training Institute, CSB, India.

Suryanarayana N, Srivastava AK (2005). Monograph on Tropical Tasar Silkworm. Central Tasar Research and Training Institute, CSB, India. Venugopal Pillai S, Krishnaswami S, Kashivishwanathan K (1987) Growth studies in silkworm, Bombyx mori. L under tropical conditions. II. Influence of agronomical methods of mulberry on growth, cocoon crop and fecundity of silkworm. Ind J Seric 26(1), 38-45.

Verma AK, Chattopadhyay GK, Sengupta M, Das SK, Sarkar A (2005) Heterobeltiotic genetic interaction between congenic and syngenic breeds of silkworm Bombyx mori L. Int J Indust Entomol 11, 119-124.

Waldbauer G (1968) The consumption and utilization of food by insect. Adv Insect Physiol 5, 229-288.

Wilson K, Walker J (2000) Kinetics of Alkaline Phosphatase In; Practical Biochemistry, Principles and Techniques. BL-304, 1-3.

Zingales B (1984) Analysis of proteins by Sodium Dodecyl SulphatePolyAcrylamide Gel Electrophoresis In: "Genes and antigens of parasites (Ed. By Morel C. M.). $2^{\text {nd }}$ Edn. Fundacao Oswaldo Cruz, Rio' de Janeiro, Brazil. pp. 357-363. 